DR. JESSICA FRAU (Orcid ID : 0000-0001-9068-9144)

DR. ROBERTA LANZILLO (Orcid ID : 0000-0001-6388-8180)

Article type : Original Article

\title{
Clinical activity after fingolimod cessation: disease reactivation or rebound?
}

\section{Running title: Clinical activity after fingolimod cessation.}

Frau J13, Sormani MP2, Signori A2, Realmuto $\mathrm{S}^{3}$, Baroncini D4, Annovazzi P4, Signoriello E5, Maniscalco G6, La Gioia $\mathrm{S}^{7}$, Cordioli $\mathrm{C}^{8}$, Frigeni $\mathrm{B}^{7}$, Rasia $\mathrm{S}^{8}$, Fenu G ${ }^{1}$, Grasso $\mathrm{R}^{9}$, Sartori $\mathrm{A}^{10}$, Lanzillo R ${ }^{11}$, Stromillo $\mathrm{ML}^{12}$, Rossi $\mathrm{S}^{13}$, Forci $\mathrm{B}^{14}$, Cocco $\mathrm{E}^{1}$ on behalf of the i-MuST study group

1. Department of Medical Sciences and Public Health, University of Cagliari, Italy. 2. Department of Health Sciences, Section of Biostatistics, University of Genova, Italy. 3. Department of Experimental Biomedicine and Clinical Neurosciences, University of Palermo, Palermo, Italy. 4. Multiple Sclerosis Study Centre, AO s.Antonio Abate, Gallarate. 5. Department of Medical, Surgical, Neurological, Metabolic and Aging Sciences, Second University of Naples, Italy. 6. Neurological Clinic and Multiple Sclerosis Centre of "AORN A.Cardarelli", Naples, Italy. 7. USC Neurologia, ASST Papa Giovanni XXIII, Bergamo, Italy. 8. Multiple Sclerosis Center, Spedali Civili of Brescia, Presidio di Montichiari, Brescia, Italy. 9. Neurologia Universitaria OORR Foggia 10. Clinica Neurologica, Azienda Ospedaliero-Universitaria Ospedali Riuniti di Trieste. 11. Department of Neurosciences, Reproductive Sciences and Odontostomatology, Multiple Sclerosis Centre, Federico II University, Naples. 12. Dept. of Medicine, Surgery \& Neuroscience, University of Siena 13. Neuroimmunology and Neuromuscular Diseases Unit, IRCCS Fondazione Istituto Neurologico Carlo Besta, Via Giovanni Celoria, 11, 20133 Milano, Italy 14. Azienda Ospedaliero Universitaria Careggi, Dipartimento di Neuroscienze, Area del farmaco e Salute del bambino (NEUROFARBA)

\section{Corresponding author:}

Prof Maria Pia Sormani

Department of Health Sciences (DISSAL)

Via Pastore 1, 16132,

Genova, Italy

tel $+39-0103538473$

mariapia.sormani@unige.it

This article has been accepted for publication and undergone full peer review but has not been through the copyediting, typesetting, pagination and proofreading process, which may lead to differences between this version and the Version of Record. Please cite this article as doi:

10.1111/ene.13694

This article is protected by copyright. All rights reserved. 


\section{Disclosures.}

J Frau serves on scientific advisory boards for Biogen and Genzyme, has received honoraria for speaking from Merck Serono, Genzyme, Biogen and Teva.

MP Sormani has received consulting fees from Biogen, Novartis, TEVA, Merck Serono, Roche, Genzyme, GeNeuro, Medday, Celgene

A Signori has received Fees from Novartis for teaching courses.

S Realmuto has received honoraria for consultancy from Merck-Serono and Teva; travel grant from Sanofi-genzyme, Novartis and Biogen.

D Baroncini has received travel grants from Genzyme, Novartis, and Merck for participation at national and international congresses; he received personal compensation from Almirall for scientific publication and honoraria from Sanofy for participating to advisory board.

P Annovazzi has received honoraria for lecturing and participation in advisory boards, and/or travel expenses for attending congresses and meetings from Merck, Biogen, Teva, SanofiGenzyme, Almirall, Mylan, Roche and Novartis.

E. Signoriello has received travel funding and speaker honoraria from Biogen, Novartis, Sanofi Genzyme, Bayer, Teva.

G.T. Maniscalco has received travel assistance and/or honoraria from, and provided advice to Biogen Idec, Novartis, Genzyme, Sanofi-Aventis and Merck-Serono.

S La Gioia has received grants from Novartis

C Cordioli has received consulting fees for speaking from Novartis, Merk Serono, TEVA, Biogen.

G Fenu has received honoraria for consultancy from Novartis and Biogen, and for speaking from Merck Serono and Teva.

A Sartori has received funding for travel and/or speaker honoraria from Teva, Novartis, Almirall, Genzyme.

R Lanzillo has received personal fees for public speaking or consultancy from Merck, Novartis, Biogen, Genzyme, Teva and Almirall.

S Rossi acted as an Advisory Board member of Biogen Idec, Bayer Schering, Merck Serono, Teva, Novartis, Mylan and Genzyme, and received funding for traveling and honoraria for speaking or writing or consultancy from Biogen Idec, Merck Serono, Teva, Novartis, Bayer Schering, Genzyme, Almirall. She received support for research project by Teva, Merck Serono and Bayer Schering. She is involved as principal investigator in clinical trials for Teva, Novartis, Biogen and Roche.

B Forci has received travel grants from Novartis, Biogen and Genzyme.

E Cocco has received honoraria for consultancy or speaking from Bayer, Biogen, Novartis, Sanofi, Genzyme, Merck and Teva.

This article is protected by copyright. All rights reserved. 
S Rasia, R Grasso, ML Stromillo, B Frigeni have nothing to disclose about this work.

\section{Funding.}

The study did not receive any funding.

Keywords: Multiple sclerosis; fingolimod; rebound; reactivation

\section{Abstract}

Objective. There is debate as to whether the apparent rebound after fingolimod discontinuation is related to the discontinuation itself, or if it is due to the natural course of highly active multiple sclerosis (MS).

We aimed to survey the prevalence of severe reactivation and rebound after discontinuation of fingolimod in a cohort of Italian patients with MS.

Methods. Patients with relapsing-remitting MS (RRMS) who were treated with fingolimod for at least 6 months and who stopped treatment for reasons that were unrelated to inefficacy were included in the analysis.

Results. A total of 100 patients who had discontinued fingolimod were included in the study. Fourteen patients (14\%) had a relapse within 3 months after fingolimod discontinuation, and an additional $12(12 \%)$ had a relapse within 6 months. According to this study's criteria, 10 patients $(10 \%)$ had a severe reactivation. Among these patients, $5(5 \%)$ had a reactivation that was considered to be a rebound.

\section{Conclusions}

The present study showed that more than $26 \%$ of patients are at risk of having a relapse within 6 months after fingolimod discontinuation. Nevertheless, the risk of severe reactivations and rebound that we found is lower than that which has been previously described.

\section{Introduction}

Fingolimod was the first oral treatment to become available for multiple sclerosis (MS). In Europe, its use is indicated for aggressive forms of relapsing-remitting (RR) MS. Data from clinical trials showed that annualized relapse rates (ARR) were more than $50 \%$ lower in subjects taking oral fingolimod as compared to subjects taking placebo [1,2]. Since 2012, several reports have described a "rebound syndrome" after fingolimod discontinuation $[3,14]$. There is not a shared definition of "clinical rebound syndrome"; the most widely used definition is "a disease reactivation which surpasses the pretreatment activity level," especially with regard to ARR $[15,16]$. The concept of "rebound" after discontinuation of treatment was first proposed for natalizumab, a monoclonal antibody approved in 2006 to

This article is protected by copyright. All rights reserved. 
treat the aggressive course of MS [17]. To date, only one study has explored the frequency of this phenomenon in patients with MS who discontinued fingolimod use. In this study, a clinical rebound syndrome was detected in 5 out of 46 subjects of a small cohort of patients who were referred to a single site (10.9\%) [18]. However, a recent post-hoc analysis of the Phase III, placebo-controlled FREEDOMS and FREEDOMS II trials did not find any difference in the emergence of clinical rebound between patients treated with fingolimod and placebo [16]. To note, the minimum time of exposure of the patients evaluated in that post-hoc analysis was 3 months, and a so short exposure may less likely to cause a rebound. In addition, the FREEDOM trials collected MRI data post fingolimod discontinuation only for 3 months, and the subjects included in the rebound analysis are a small fraction of those enrolled.

While there is agreement in the literature that there is a high risk of rebound after natalizumab discontinuation [17], the concept of rebound after fingolimod cessation is less well defined.

The aim of this multicenter study was to evaluate the presence of clinical rebound syndrome after fingolimod discontinuation in a cohort of Italian patients with MS.

\section{Materials and methods.}

The patients who were enrolled in this study were recruited from 14 Italian MS centers between March and October 2017, after signed informed consent. The study was approved by the local ethics committees. The inclusion criteria were as follows: diagnosis of RRMS according to the McDonald criteria, previous treatment with fingolimod for at least 6 consecutive months over the person's lifetime, an absence of relapses in the last 6 months of treatment with fingolimod, and suspension of fingolimod due to reasons other than inefficacy (i.e., desire to become pregnant, side effects, self-discontinuation). In following the Italian Agency of Drug (AIFA) dispositions, all subjects started fingolimod due to aggressive disease from the onset (naïve patients), inefficacy of first-line treatments (switching patients), or a high risk of progressive multifocal leukoencephalopathy (PML) during natalizumab therapy. At each center from which patients were recruited, a neurologist with expertise in MS diagnosis and treatment collected the following demographic and clinical information from the patients' data records: gender; year of birth; age at onset; comorbidities; the last disease modifying drug (DMD) before fingolimod and the first DMD after its discontinuation; reason for suspension of fingolimod; ARR before, during, and after fingolimod; and Expanded Disability Status Scale (EDSS) score at the time that fingolimod was started and stopped, as well as during the post-suspension relapses.

A severe reactivation was defined as a relapse with an associated EDSS increase of at least 2 points or as 2 or more relapses in the 6 months following fingolimod discontinuation. A rebound was defined when a so high clinically severe reactivation, as previously described,

This article is protected by copyright. All rights reserved. 
was never reported in patient's lifetime before fingolimod discontinuation. Thus, if the patient experienced the same severe disease activity both after fingolimod cessation and before (in any period of the course of the disease), that reactivation was not considered a rebound.

\section{Statistical analysis}

Quantitative results are presented as mean and standard deviation (SD) or median with the interquartile range (IQR). Absolute counts and percentages are reported for counts and binary variables. To evaluate demographic and clinical features as possible prognostic factors for severe reactivation after discontinuation of fingolimod, comparisons between patients with and without a severe reactivation were made using an independent samples Student's t test (age at first dose of fingolimod), a non-parametric Mann-Whitney U test (disease duration at first dose of fingolimod, duration of fingolimod treatment, EDSS score at fingolimod discontinuation, and ARR in the year before fingolimod initiation), and a chi-square test (gender and comorbidities). A p-value of $<0.05$ was considered statistically significant. Statistical analyses were performed with Stata (v.14; StataCorp) software.

\section{Results}

A total of 100 patients, 80 female (80\%) and 20 male (20\%), were included in the study. The mean age at onset was 27 years (SD: 8.7). At the time that fingolimod was started, the median EDSS and the mean duration of the disease were 2 (IQR: 1.5-3.5) and 10.7 (SD: 6.8), respectively. The median EDSS at the end of the treatment was 2 (IQR: 1-3.5). The mean duration of fingolimod treatment was 1.9 years (SD: 1.5 , range: $0.5-5.9$ ).

The vast majority of patients $(70,69.3 \%)$ started fingolimod therapy due to inefficacy of the first-line treatment, whereas $26(25.75 \%)$ switched from natalizumab due to the high risk of PML and 5 (4.95\%) had an aggressive course of the disease and were naïve to DMDs. The reasons for discontinuation of fingolimod were side effects or adverse events in 57 patients (57\%), the desire to become pregnant in 33 patients (33\%), and the patient's choice in 10 patients $(10 \%)$.

After fingolimod, a new DMD was started in 72 patients within a median time of 3 months (IQR: 1.1-6.1). Sixty subjects did not experience any relapse after fingolimod discontinuation during the whole follow-up. Of them, 40 started a new DMD after a mean time of 5 months (IQR: 0.9-4.8). The ARR before, during, and after fingolimod regarding the whole cohort of patients is shown in figure 1.

Forty subjects had a relapse during the follow-up. In particular, 14 out of 100 patients (14\%) had a relapse within 3 months after fingolimod discontinuation (only 1 started a new therapy within 3 months from the time that fingolimod was discontinued), and an additional 12 patients $(12 \%)$ had a relapse within 6 months ( 5 started a new therapy within 6 months from the time that fingolimod was discontinued). According to the above-mentioned criteria, 10

This article is protected by copyright. All rights reserved. 
patients (10\%) had a clinically severe reactivation. Among them, 1 had a relapse associated with an EDSS increase of 6 points, 2 had a relapse associated with an EDSS increase of 3.5 points, 2 had a relapse associated with an EDSS increase of 2 points, and 5 had at least 2 relapses over 6 months. Upon analysis of the patients with severe reactivation, 5 of them (5\% of the whole cohort) were defined as having had a clinical rebound. The demographic and clinical features of patients who experienced severe reactivation and rebound of the disease after discontinuation of fingolimod are reported in table 1.

From the analysis of clinical and demographic features, we were not able to detect significant prognostic factors for severe reactivation of disease. However, patients with a severe reactivation were younger and all were female. The detailed results are presented in table 2 . The details about EDSS course, new and enhancing lesions on the brain MRI, and features of clinical reactivation are reported in the table 3.

\section{Discussion}

We conducted a retrospective, observational, real-life study involving a cohort of MS patients who were treated with fingolimod and who discontinued therapy for reasons other than poor efficacy. According to AIFA dispositions, when fingolimod was started all of the patients had an aggressive disease course, defined either as at least one relapse during interferon beta or glatiramer acetate treatment, or at least 2 relapses in the last year if the patient was not taking a DMD. Moreover, the patients' disease was stable during treatment, and the treatment was discontinued for side effects, the desire to become pregnant, or reasons other than inefficacy. In our cohort, $10 \%$ of patients experienced a severe reactivation of MS, and the reactivations of half of these patients met the definition of clinical rebound syndrome. As proposed in the recent analysis of the FREEDOMS and FREEDOMS II trials [16], patients experiencing a severe reactivation after discontinuation of fingolimod may simply have had a high level of MS activity, as compared to their pre-fingolimod clinical histories, which would be expected as part of the natural, unpredictable course of the disease.

It is worth noting that some of the clinical case studies that have described a rebound after fingolimod discontinuation [6-9,13], including the small cohort that was described by Hatcher et al [18], studied patients in which fingolimod was discontinued due to a lack of efficacy. Given that these patients did not respond to fingolimod, a reactivation of the disease would be expected upon therapy discontinuation. Recently, a high relapse rate and a low EDSS score before fingolimod treatment have been hypothesized to be negative prognostic factors for severe disease reactivation within the first 3 months after cessation of the therapy [19]. In our study, we were not able to identify factors that were strongly associated with severe reactivation after discontinuation of fingolimod. It is important to note, however, that all the patients with severe reactivation were female and were also younger than the other subjects, despite the fact that these differences did not reach statistical significance. This may have been due to the low statistical power of these comparisons.

This article is protected by copyright. All rights reserved. 
Currently, there is no agreement on the pathological explanation for the supposed rebound. It is possible that it is related to a rapid lymphocyte reconstitution [18], but such a reconstitution has not been observed in all patients with a rebound. A more likely hypothesis is that a differential lymphocyte subset repopulation may be driving the rebound syndrome [20]. Moreover, it has been shown in the experimental model of MS, that rebound after fingolimod discontinuation is preceded by an overexpression of S1P1 in lymphocytes entrapped in lymph nodes, and it correlate with their massive egress from lymph nodes and with infiltrates in the Central Nervous System [21].

One important limitation of this study is that rebound was considered only on the basis of clinical, but not radiological, features. This is due to the observational and retrospective design of this study, in which data collected in clinical practice was analyzed. MRI examinations were not homogeneously performed across centers, both in terms of imaging protocols and in terms of timing of the scanning, and only a few patients underwent an MRI examination within the first 6 months after fingolimod discontinuation. Of note, clinical and radiological rebounds were considered as two separate entities in the analysis of the FREEDOMS and FREEDOMS II studies [16]. Another limitation, due to the fact that it is a real life study, is the lack of lymphocyte subset after fingolimod discontinuation for the vast majority of patients. That being said, the cohort of patients included in this study was selected from specialized Italian MS centers that belong to the research group iMUST. Given their participation in iMUST, these centers share relatively homogeneous rules for MS treatment and for strict observation of AIFA dispositions. In accordance with these prescriptive rules, only patients who fail a first line treatment, and those with aggressive course of MS from the onset of the disease could take fingolimod. Thus, all the patients had an aggressive course before the fingolimod initiation.

In conclusion, the rate of rebound after fingolimod discontinuation was estimated to be $5 \%$ in this relatively large case series, which is a lower risk than that which was previously described in another real-life cohort [18]. These data could have an important impact in the physician-patient communication, both when fingolimod is proposed as new therapy, and when it has to be stopped due to any kind of reason. Moreover, even if the risk emerged from our study is not so high as previously described, it has to be considered every time when fingolimod is discontinued. To confirm our results, it could be important to conduct other real-life studies analyzing the impact of clinical, and possibly, radiological rebound after fingolimod cessation in RR MS patients without disease activity before the discontinuation.

This article is protected by copyright. All rights reserved. 


\section{References.}

1. Kappos L, Radue EW, O'Connor P, et al. A placebocontrolled trial of oral fingolimod in relapsing multiple sclerosis. N Engl J Med 2010; 362: 387-401.

2. Calabresi PA, Radue EW, Goodin D, et al. Safety and efficacy of fingolimod in patients with relapsing-remitting multiple sclerosis (FREEDOMS II): A double-blind, randomised, placebocontrolled, phase 3 trial. Lancet Neurol 2014; 13: 545-556.

3. Havla JB, Pellkofer HL, Meinl I, et al. Rebound of disease activity after withdrawal of fingolimod (FTY720) treatment. Arch Neurol. 2012;69(2):262-4.

4. Hakiki B, Portaccio E, Giannini M, et al. Withdrawal of fingolimod treatment for relapsingremitting multiple sclerosis: report of six cases. Mult Scler. 2012;18(11):1636-9.

5. Beran RG, Hegazi Y, Schwartz RS, Cordato DJ. Rebound exacerbation multiple sclerosis following cessation of oral treatment. Mult Scler Relat Disord. 2013;2(3):252-5.

6. Berger B, Baumgartner A, Rauer S, et al. Severe disease reactivation in four patients with relapsing-remitting multiple sclerosis after fingolimod cessation. J Neuroimmunol. 2015;282:118-22.

7. Forci B, Mariottini A, Mechi C, et al. Disease reactivation following fingolimod withdrawal in multiple sclerosis: Two case reports. Mult Scler Relat Disord. 2017;15:24-26.

8. Ghezzi A, Rocca MA, Baroncini D, et al. Disease reactivation after fingolimod discontinuation in two multiple sclerosis patients. J Neurol. 2013;260(1):327-9.

9. Gündüz T, Kürtüncü M, Eraksoy M. Severe rebound after withdrawal of fingolimod treatment in patients with multiple sclerosis. Mult Scler Relat Disord. 2017;11:1-3.

10. Gross CM, Baumgartner A, Rauer S, Stich O. Multiple sclerosis rebound following herpes zoster infection and suspension of fingolimod. Neurology. 2012;79(19):2006-7.

11. La Mantia L, Prone V, Marazzi MR, et al. Multiple sclerosis rebound after fingolimod discontinuation for lymphopenia. Neurol Sci. 2014;35(9):1485-6.

12. Novi G, Ghezzi A, Pizzorno M, et al. Dramatic rebounds of MS during pregnancy following fingolimod withdrawal. Neurol Neuroimmunol Neuroinflamm. 2017;4(5):e377.

13. Piscolla E, Hakiki B, Pastò L, et al. Rebound after Fingolimod suspension in a pediatriconset multiple sclerosis patient. J Neurol. 2013;260(6):1675-7.

14. Faissner $\mathrm{S}$, Hoepner R, Lukas $\mathrm{C}$, et al. Tumefactive multiple sclerosis lesions in two patients after cessation of fingolimod treatment. Ther Adv Neurol Disord. 2015;8(5):233-8.

15. Członkowska A, Smoliński Ł, Litwin T. Severe disease exacerbations in patients with multiple sclerosis after discontinuing fingolimod. Neurol Neurochir Pol. 2017;51(2):156-162.

This article is protected by copyright. All rights reserved. 
16. Vermersch P, Radue EW, Putzki N, et al. A comparison of multiple sclerosis disease activity after discontinuation of fingolimod and placebo. Mult Scler J Exp Transl Clin.

2017;3(3):2055217317730096.

17. Clerico M, Artusi CA, Liberto AD, et al. Natalizumab in Multiple Sclerosis: Long-Term Management. Int J Mol Sci. 2017;18(5).pii: E940.

18. Hatcher SE, Waubant E, Nourbakhsh B, et al. Rebound Syndrome in Patients With Multiple Sclerosis After Cessation of Fingolimod Treatment. JAMA Neurol. 2016;73(7):790-4.

19. Uygunoglu U, Tutuncu M, Altintas A, et al. Factors Predictive of Severe Multiple Sclerosis Disease Reactivation After Fingolimod Cessation. Neurologist 2018;23(1):12-16.

20. Song ZY, Yamasaki R, Kawano Y, et al. Peripheral blood T cell dynamics predict relapse in multiple sclerosis patients on fingolimod. PLoS One. 2015 Apr 28;10(4):e0124923.

21. Cavone R, Felici L, lapucci A, et al. Dysregulation of sphingosine 1 phosphate receptor-1 (S1P1) signaling and regulatory lymphocyte-dependent immunosuppression in a model of post-fingolimod MS rebound. Brain Behav Immun. 2015 Nov;50:78-86

Table 1

Demographic and clinical features of patients who experienced severe reactivation of disease after fingolimod discontinuation.

Pt: patients; IFN: interferon beta; nat: natalizumab; GA: glatiramer acetate; AE: adverse event; fingo: fingolimod

\begin{tabular}{|c|c|c|c|c|c|c|c|c|c|c|c|c|c|c|c|c|c|c|}
\hline $\mathrm{Pt}$ & Rebound & Gender & Age at onset & $\begin{array}{l}\text { DMD pre } \\
\text { fingo }\end{array}$ & $\begin{array}{c}\text { Relapses } 12 \\
\text { months } \\
\text { before fingo }\end{array}$ & $\begin{array}{c}\text { MRI before } \\
\text { fingo: new } \\
\text { T2 }\end{array}$ & $\begin{array}{l}\text { MRI before } \\
\text { fingo: Gd+ }\end{array}$ & Comorbidity & $\begin{array}{l}\text { Washout } \\
\text { pre fingo } \\
\text { (months) }\end{array}$ & $\begin{array}{c}\text { Disease } \\
\text { duration at } \\
\text { fingo start } \\
\text { (years) }\end{array}$ & \begin{tabular}{|c|} 
EDSS at \\
fingo \\
start
\end{tabular} & \begin{tabular}{|l|} 
EDSS at \\
fingo \\
stop
\end{tabular} & $\begin{array}{c}\text { EDSS } \\
\text { during } \\
\text { reactivation }\end{array}$ & $\begin{array}{l}\text { Reason for } \\
\text { suspension }\end{array}$ & $\mid \begin{array}{c}\text { Lymphocytes } \\
\text { after } \\
\text { suspension }\end{array}$ & $\begin{array}{l}\text { Time to } \\
\text { Iymphocytes count } \\
\text { after suspension } \\
\text { (months) }\end{array}$ & $\begin{array}{l}\text { DMD } \\
\text { post } \\
\text { fingo }\end{array}$ & $\begin{array}{c}\text { Time to } \\
\text { new drug } \\
\text { (months) }\end{array}$ \\
\hline 1 & yes & Female & 20 & nat & 0 & no & no & none & 5 & 5 & 1 & 2 & 2.5 & \begin{tabular}{|l|} 
Pregnancy \\
\end{tabular} & 1200/ul & 2 & alem & 3.7 \\
\hline$\frac{2}{2}$ & yes & & 25 & nat & $\frac{1}{104}$ & not available & not available & & 7 & 14 & 5.5 & 5 & 8.5 & \begin{tabular}{|l} 
Pt decision \\
\end{tabular} & not available & & none & \\
\hline$\frac{2}{3}$ & $\frac{y 0 s}{\text { yes }}$ & Female & 14 & nat & 0.81 & no & no & none & 7 & 16 & 3 & 3 & 9 & Pregnancy & \begin{tabular}{|l|l|l|}
$1100 / \mathrm{ul}$ \\
\end{tabular} & 7 & DMF & 5.9 \\
\hline 4 & yes & Female & 21 & IFN & 1.5 & yes & yes & epilepsy & 1 & 4 & 1.5 & 2 & 4 & $A E$ & \begin{tabular}{|l|} 
not available \\
\end{tabular} & & nat & 8.1 \\
\hline 5 & yes & Female & 26 & nat & 0 & no & no & none & 6 & 12 & 2 & 2 & 3 & $\mathrm{AE}$ & $2140 / \mathrm{ul}$ & 0 & nat & 5.0 \\
\hline 6 & no & Female & 24 & IFN & 2 & no & & headache & 2 & 21 & 2.5 & 2.5 & 3 & $A E$ & 116 & 1 & IFN & 2.9 \\
\hline & no & Female & 25 & IF & 1 & not available & not available & none & 0 & 13 & 1 & 1 & 2 & \begin{tabular}{|l|} 
Pregnancy \\
\end{tabular} & not available & & GA & 0.8 \\
\hline 8 & no & Female & 28 & $\mathrm{GA}$ & 0.84 & no & no & none & 2 & 13 & 3.5 & 4 & 6 & \begin{tabular}{|l|l|} 
Pt decision \\
\end{tabular} & 121 & 0 & terifl & 0.6 \\
\hline & no & Female & 14 & $\pi$ & 2 & yes & yes & sine & 6 & 7 & 1.5 & 0 & 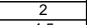 & & & 3 & GA & 3.7 \\
\hline 10 & no & Female & 20 & nat & 0 & not available & not available & none & 4 & 6 & 2 & & 4.5 & $\mathrm{AE}$ & $1000 /$ ul & 0 & ritux & 2.3 \\
\hline
\end{tabular}

This article is protected by copyright. All rights reserved. 
Table 2.

Demographic and clinical features in patients with no severe reactivation, with severe disease reactivation, and with rebound.

ARR: annualized relapse rate; EDSS: Expanded Disability Status Scale

\begin{tabular}{|c|c|c|c|}
\hline & $\begin{array}{l}\text { No severe } \\
\text { reactivation } \\
(\mathrm{n}=90)\end{array}$ & $\begin{array}{l}\text { Severe } \\
\text { reactivation } \\
(\mathrm{n}=10)\end{array}$ & Rebound $(n=5)$ \\
\hline $\begin{array}{l}\text { Age at first dose of fingolimod, mean } \\
\text { (SD); range }\end{array}$ & $\begin{array}{l}38.2(10.2) ; 18- \\
60\end{array}$ & $\begin{array}{l}32.9(8.4) ; 21- \\
45\end{array}$ & $\begin{array}{l}31.6(6.9) ; 25- \\
39\end{array}$ \\
\hline Female, n(\%) & $70(77.8)$ & $10(100)$ & $5(100)$ \\
\hline $\begin{array}{l}\text { Disease duration at first dose of } \\
\text { fingolimod (years), mean (SD); } \\
\text { median }\left(25^{\text {th }}-75^{\text {th }}\right)\end{array}$ & $\begin{array}{l}10.6(7) ; 8.7 \\
(5.1-15.2)\end{array}$ & $\begin{array}{l}11.3(5.5) ; 12.2 \\
(5.6-14.5)\end{array}$ & $\begin{array}{l}10.5(5.5) ; 12 \\
(5.3-14.5)\end{array}$ \\
\hline $\begin{array}{l}\text { Duration of fingolimod treatment } \\
\text { (months), mean }(S D) ; \text { median }\left(25^{\text {th }} \text { - }\right. \\
\left.75^{\text {th }}\right)\end{array}$ & $\begin{array}{l}25.5 \text { (13.1); } \\
25.9 \text { (18-28.9) }\end{array}$ & $\begin{array}{l}22.6(17) ; 18.3 \\
(10.7-30.1)\end{array}$ & $\begin{array}{l}26.5 \text { (13.1); } \\
18.2(18-39)\end{array}$ \\
\hline Comorbidities pre-fingolimod, $\mathrm{n}(\%)$ & $51(56.7)$ & $6(60)$ & $2(40)$ \\
\hline ARR before fingolimod, mean(SD) & $0.87(0.77)$ & $0.92(0.76)$ & $0.66(0.65)$ \\
\hline $\begin{array}{l}\text { EDSS at fingolimod cessation, median } \\
\left(25^{\text {th }}-75^{\text {th }} \text { percentile }\right)\end{array}$ & $2(1-3.5)$ & $2(1-3)$ & $2(2-3)$ \\
\hline
\end{tabular}

Table 3

EDSS course, and MRI and reactivation features in patients who experienced a rebound.

\begin{tabular}{|c|c|c|c|c|c|c}
\hline Pt & $\begin{array}{c}\text { EDSS before } \\
\text { fingolimod }\end{array}$ & $\begin{array}{c}\text { EDSS at the } \\
\text { end of } \\
\text { fingolimod }\end{array}$ & $\begin{array}{c}\text { EDSS during } \\
\text { the } \\
\text { reactivation }\end{array}$ & $\begin{array}{c}\text { MRI new T2 } \\
\text { lesions }\end{array}$ & $\begin{array}{c}\text { MRI Gd+ } \\
\text { lesions }\end{array}$ & $\begin{array}{c}\text { Type of reactivation within } 6 \text { months from } \\
\text { discontinuation }\end{array}$ \\
\hline 1 & 1 & 2 & 2.5 & yes & yes & 2 relapses \\
\hline 2 & 5.5 & 5 & 8.5 & yes & yes & 2 relapse and EDSS increase $>2$ points \\
\hline 3 & 3 & 3 & 9 & yes & yes & one relapse with EDSS increase $>2$ points \\
\hline 4 & 1.5 & 2 & 4 & yes & yes & 2 relapse and EDSS increase $>2$ points \\
\hline 5 & 2 & 2 & 3 & yes & yes & 3 relapses
\end{tabular}

Figure 1.

Representation of the annualized relapse rate (ARR) before, during, and after fingolimod in three groups of patients: those without relapses after fingolimod discontinuation, those who experienced reactivation, and those who experienced a rebound of the disease.

This article is protected by copyright. All rights reserved. 


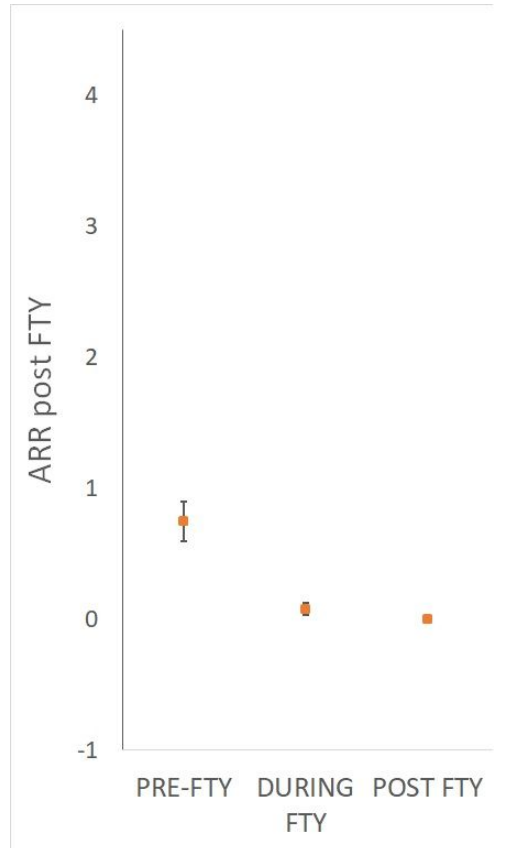

NO RELAPSES POST FTY

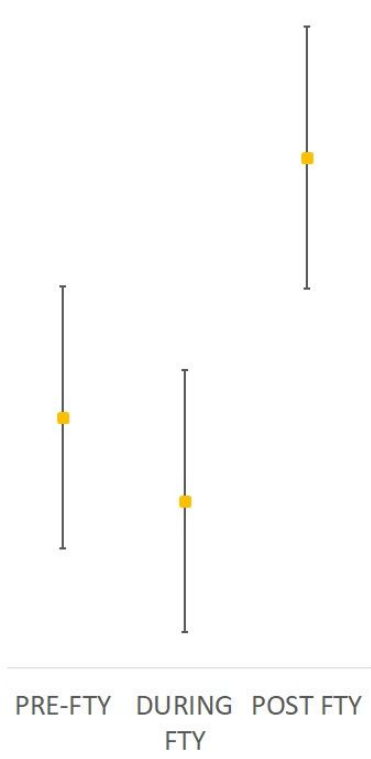

REACTIVATION
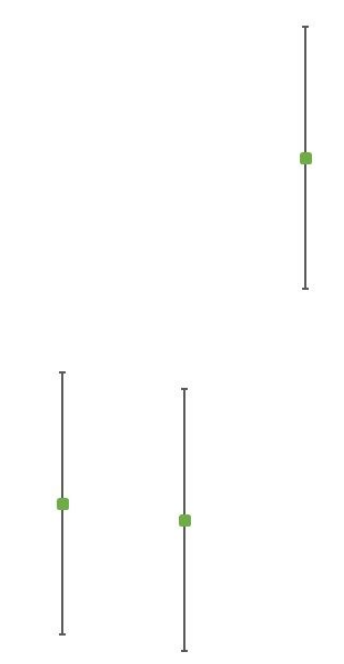

PRE-FTY DURING POST FTY FTY

REBOUND

This article is protected by copyright. All rights reserved. 